\title{
Factors affecting acceptance of VCT among different professional and community groups in North and South Gondar Administrative zones, north west Ethiopia
}

\author{
Mengesha Admassu', Yohannis Fitaw ${ }^{2}$
}

\begin{abstract}
Background: Voluntary counseling and testing (VCT) for HIV allows individuals to determine their HIV status and serve as a gateway for both HIV prevention and early access to treatment, care and support. Identifying factors associated with VCT acceptance among different professional and community groups is essential in promoting the service.

Objective: The aim of this study is to assess factors that affect VCT acceptance among different professional and community groups in the north and south Gondar administrative zones of north west Ethiopia.

Methods: A cross-sectional descriptive study was undertaken among different professional and community groups in north and south Gondar administrative zones using a pre-tested structured questionnaire on a total of 460 respondents from October - December 2004.

Results: Four hundred forty people granted interviews from a total of 460 proposed study participants with a response rate of $96 \%$. The mean age of the respondents was 27.79 years. Sixty five percent of the respondents were males and the rest were females. Eighty two percent of the respondents were willing to accept VCT services. The age range from 15-19 years was found to be positively associated with VCT acceptance $(\mathrm{p}<0.01)$. Results of the behavioural variables showed the effect of others (friends families, religious leaders, and couples) who were found to have statistically very significant effect towards VCT acceptance $(\mathrm{p}<0.001)$. The absence of community support was found to be negatively associated with VCT acceptance $(\mathrm{p}<0.01)$. The availability of ART was found to have positive association with acceptance of VCT $(\mathrm{p}<0.001)$.

Conclusion: Involving closely related people is instrumental in enhancing the social acceptance of voluntary counseling and testing and providing sustainable and reliable VCT services. Increasing access to ART services would also help in further expanding VCT services. [Ethiop.J.Health Dev. 2006;20(1):24-31]
\end{abstract}

\section{Introduction}

The impact of HIV/AIDS goes beyond public health concerns because it primarily affects adult populations in the productive and reproductive age groups and, as such, in its endemic stage, undermines the social and economic structures of developing countries (1). The report on the Global AIDS Epidemic released in 2004 indicated the estimated number of people living with HIV to be adults and children-37,800,000; 25,000,000 and 1,500,000 globally, in sub-Saharan Africa and Ethiopia respectively (2).

The HIV/AIDS situation in Ethiopia has evolved from two reported AIDS cases in 1986 to a cumulative total of 147,000 by mid 2003. It is currently estimated that 1.5 million people are living with HIV/AIDS and this is a staggering number to cope with in a resource-poor country (3). Out of the 23,861 people from whom the National Sentinel Surveillance (NSS) samples were obtained in 2003, 8.2\% (4.1\% rural and $12 \%$ urban) were found to be HIV positive. The estimated HIV prevalence in the Amhara National Regional State, where the study zones are located, was about $11 \%$; and the prevalence in urban and rural areas of Gondar town was $14 \%$ and $8 \%$ respectively (3).

Voluntary HIV counseling and testing is the process by which an individual undergoes counseling enabling him or her to make an informed choice about being tested for HIV (1). Many studies have found that VCT is effective as a strategy for facilitating behavioral change around both preventing HIV as well as getting early access to care and support. It is also showed that VCT is instrumental in bringing about behavioral change, reducing unprotected sex and helping reduce the incidence of HIV and other STIs (4-9).

Many people in Ethiopia living with HIV do not know that they are infected. Up until now, only a small percentage of those with HIV/AIDS have had access to reliable voluntary counseling and testing services. As there is no cure for HIV/AIDS, voluntary HIV counseling and testing remains a key strategy to control the spread of HIV and to provide care and support to those who live with the virus (1).

Various studies undertaken in Ethiopia have shown a lack of perception of being at risk, no consideration for VCT services, fear of HIV positive results and fear of stigma to be some of the reasons why people are not seeking pre-marital VCT. In another study it was shown that having an educational status of secondary school and above, being female and being Christian were associated with willingness to take VCT (10-12). However there

\footnotetext{
${ }^{1}$ Department of Environmental Health Gondar College of Medicine and Health Sciences, UOG, P.O. Box 196, Gondar, Ethiopia; ${ }^{2}$ Departmet of Community Health Gondar College of Medicine and Health Sciences, UoG
} 
was a lack of such studies in north western Ethiopia where this study was conducted. Identifying factors which play detrimental roles in the acceptance of voluntary counseling and testing services helps in removing those barriers to accessing the service. Examining and understanding factors associated with VCT acceptance is also a vital and timely activity to facilitate HIV prevention efforts. These determinant factors are expected to differ from community to community. The impact of identifying factors affecting VCT acceptance also helps to promote the services in the prevention and control of HIV/AIDS. The designing of VCT services tailored to the different needs of various community groups should be based on empirical findings in each specific area. This study intends to identify factors operating among different community, professional and community groups in north and south Gondar and which are believed to affect the acceptance of VCT services. Hence, the finding of this study is expected to help VCT program designers to tackle different contextual factors that hinder the service.

\section{Methods}

Study design: A cross-sectional descriptive design was employed in this study.

Study area: The study was conducted in North and South Gondar administrative zones, north western Ethiopia, from October - December, 2004. The two zones were selected for better representation of the area. Two out of ten woredas (administrative units) of south Gondar and three out of eighteen woredas of the north Gondar were included in the study. The total number of woredas included in the study was limited to five out of eighteen woredas of the two respective zones for logistical reasons. The five woredas were randomly selected from the total number of woredas in the two zones. A total of 18 different groups with professional and community members, i.e. six groups from south Gondar and 12 groups from north Gondar were selected for the study.

Study population: The different professional groups (teachers, health professionals, etc) and community groups (eg. Idir, women's associations, and youth's associations etc) found in north and south Gondar was taken as source populations. The selected groups were identified as pre-organized community, professional and community groups in the selected woredas. Being in the age of fifteen and above was one inclusion criteria in the selection of the study subjects.

Sample size: The sample size was determined by assuming a positive attitude towards VCT $(50 \%)$ to obtain the maximum sample size, with a 3\% margin of error and a $95 \%$ confidence level and with a $20 \%$ noresponse rate. The calculated total sample size was 460 people from eighteen different professional and community groups.

Sampling method: A non-probability purposive sampling technique was considered due to the fact that the study groups were selected by the judgment of the researchers. Each group had an average of 25 participants based on an equal allocation of the total study subjects to the selected 18 professional and community groups. In cases where there were two or more professional and community groups of similar types in one woreda, one was selected by simple random sampling method to avoid selection bias and for better representation.

Data collection instruments: Structured questionnaires were used to collect data. The questionnaire adapted from the ones used for conducting the first Behavioral Surveillance Survey (BSS) of Ethiopia. The questionnaire contained questions related to sociodemographic characteristics, knowledge about HIV/AIDS and VCT, attitude towards acceptance of $\mathrm{VCT}$, cost of VCT, proximity to health institutions; stigma and discrimination; previous sexual behavior; perceived benefits; perceived barriers; perceived susceptibility cues to action and significant others. Four qualified nurses were trained for two days and were made to participate in the pre-testing of the questionnaire and collecting of data. The data collectors interviewed the study subjects using pre-tested and structured questionnaires. The principal investigators supervised the data collection, and incomplete and inconsistent data were identified and the necessary corrections were made on the field.

Data analysis: The data entry, cleaning and analysis was performed using SPPS version 10 statistical program. For different variables, frequencies, odds ratio (OR), 95\% CI and P-value at 5\% percent were computed to assess the process and degree of association between dependent and independent variables and results were compared.

Ethical consideration: Ethical clearance was obtained from the Research \& Publications Office (RPO) of the University of Gondar. An official letter of cooperation was written to the 18 groups in the five woredas and informed consent was obtained from the participants and confidentiality was maintained.

\section{Results}

A total of 440 people responded to the questionnaire from the 460 proposed study participants with a response rate of $96 \%$. The proportion of males and females was $65 \%$ to $35 \%$ respectively. The mean $(+\mathrm{SD})$ age of the study subjects was $27.79(+10.8)]$ years with a median age of 25 years. Seventy three percent of the respondents were grade nine \& above and those without formal 
education constituted $4.5 \%$. The majority of the study participants were Orthodox Christians (94\%) while the rest were Protestants and Muslims. Regarding ethnicity, Amhara comprised $90 \%$, Tigre (5\%) and others (5\%) (Table 1).

Table 1: Socio-demographic characteristics of members of different professional and community group in north and south Gondar, November 2004

\begin{tabular}{|c|c|c|}
\hline Variables & $\begin{array}{l}\text { Frequency } \\
(\mathrm{N}=440)\end{array}$ & $\begin{array}{l}\text { Percent } \\
(\%)\end{array}$ \\
\hline \multicolumn{3}{|l|}{ Place of residence by zones } \\
\hline Urban & 351 & 79 \\
\hline Rural & 89 & 21 \\
\hline \multicolumn{3}{|l|}{ Sex of the study subjects } \\
\hline Male & 287 & 65 \\
\hline Female & 153 & 35 \\
\hline \multicolumn{3}{|l|}{ Age $[$ Mean $(+S D)=27.79(+10.8)]$} \\
\hline $15-19$ & 114 & 25.9 \\
\hline $20-29$ & 175 & 39.8 \\
\hline $30-39$ & 79 & 17.9 \\
\hline 40 and above & 72 & 16.4 \\
\hline \multicolumn{3}{|l|}{ Educational status } \\
\hline No formal education & 20 & 4.5 \\
\hline Grade 1-4 & 47 & 10.7 \\
\hline Grade 5-8 & 50 & 11.4 \\
\hline Grad 9-12 & 182 & 41.4 \\
\hline Grade 12 and above & 141 & 32.0 \\
\hline \multicolumn{3}{|l|}{ Religion } \\
\hline Orthodox & 400 & 91.0 \\
\hline Muslim & 29 & 6.6 \\
\hline Protestant & 11 & 2.5 \\
\hline \multicolumn{3}{|l|}{ Woreda level } \\
\hline Gondar town & 138 & 31.4 \\
\hline Fogera & 84 & 19.1 \\
\hline Debretabor & 78 & 17.7 \\
\hline Chelga & 76 & 17.3 \\
\hline Dabat & 64 & 14.5 \\
\hline \multicolumn{3}{|l|}{ Ethnicity } \\
\hline Amhara & 396 & 90 \\
\hline Tigrie & 22 & 5 \\
\hline Oromo & 11 & 2.5 \\
\hline Others & 11 & 2.5 \\
\hline \multicolumn{3}{|l|}{ Professional groups } \\
\hline Commercial sex workers & 26 & 5.9 \\
\hline Constructional workers & 24 & 5.5 \\
\hline Defense army & 25 & 5.7 \\
\hline Heavy trucks drivers & 14 & 3.2 \\
\hline large industrial workers & 18 & 4.1 \\
\hline Farmers & 20 & 4.5 \\
\hline Hospital health staffs & 25 & 5.7 \\
\hline High school students & 28 & 6.4 \\
\hline HIV club members & 27 & 6.1 \\
\hline BSc. Nurse students & 26 & 5.9 \\
\hline Military police & 30 & 6.8 \\
\hline Woreda pool workers & 30 & 6.8 \\
\hline Teacher training students & & \\
\hline (Pedagogy) & 26 & 5.9 \\
\hline High school teachers & 26 & 5.9 \\
\hline \multicolumn{3}{|l|}{ Community Groups } \\
\hline People at corrections (prisoners) & 25 & 5.7 \\
\hline Idir & 21 & 4.8 \\
\hline Women association & 26 & 5.9 \\
\hline Youth & 23 & 5.2 \\
\hline
\end{tabular}

The highest VCT acceptance was observed among those study subjects aged 15 to 19 years where $104(91.2 \%)$ opted to accept VCT while the least VCT acceptance was seen among those aged 40 years and above with 52 (72.2\%) who were willing to accept VCT. Of the sociodemographic variables considered to affect VCT acceptance, the age group of 15-19 showed positive association with VCT acceptance four times greater than the other age group with an OR of $4.00(1.63,9.96)$ (Pvalue $<0.01$ ) (Table 2).

On bivariate analysis, the association between acceptance of VCT and educational level was not found to be significant. Health professionals and high school teachers were found to be 0.12 and 0.06 times less likely to accept VCT compared with the other professional and community groups included in the study with an OR of $0.12(0.02,0.73)(\mathrm{P}$-value $<0.01)$ and $0.06(0.05,0.36)(\mathrm{P}-$ value $<0.001$ ) respectively (Table 2 ).

Of the total number of respondents, 248 (56.4\%) said they knew people living with HIV/AIDS while 229 (52.1\%) said they knew a person who had died of HIV/AIDS. Eighty two percent of the respondents were willing to accept VCT (Table 3). The respondents were asked if knowing one's sero status could result in being stigmatized and consequently affects VCT acceptance. It was found out that those who stated stigma could come from knowing (disclosing) one's status were 0.4 times less likely to accept VCT with an OR of $0.40(0.23,0.69)$ (P-value $<0.001)$ (Table 3).

Thirty three percent of the respondents believed that if one decides to have VCT, he/she would not have community support. Among those who said that deciding to have VCT testing would entail a lack of community support, $111(25.2 \%)$ were willing to accept VCT while those who said otherwise-250 (57\%) were willing to accept VCT. This shows that the lack of community support was negatively associated with half times lower VCT acceptance in the presence of community support with an OR of $0.53(0.31,0.90)$ (Pvalue $<0.01$ ) (Table 3 ).

About 369 (83.8\%) of the respondents were willing to be tested if ART were available. The availability of ART was positively associated with acceptance of VCT which 
is about 7 times higher than the case with the unavailability of ART with an OR of $7.18(3.95,13.10)$ (P-value $<0.001)$. After controlling for the confounding effect to socio-demographic variables, the availability of
ART as an important predictor of VCT acceptance remained significant with an OR of $4.46(2.24,8.87)$ (Pvalue $<0.001)$ (Table 3$)$.

Table 2: Acceptance of VCT Vs Socio-demographic variables $(n=440)$ of different professional and community group in north and south Gondar, November 2004.

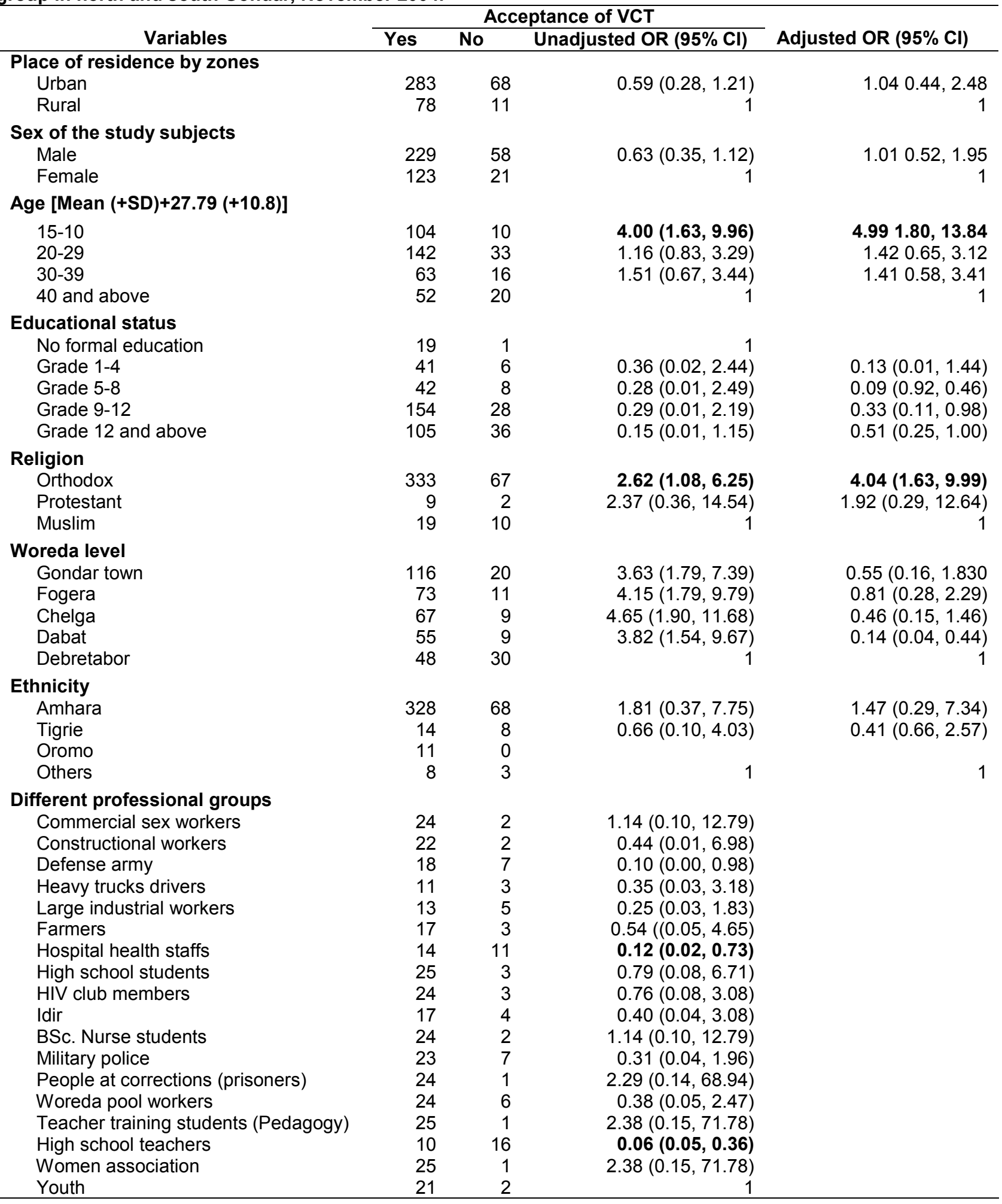


Table 3: Acceptance of VCT Vs knowledge, attitudes and practice variables $(n=440)$ of different professional and community groups in north and south Gondar administrative zones, Gondar, November 2004.

\begin{tabular}{|c|c|c|c|c|}
\hline \multirow{2}{*}{ Variables } & \multicolumn{3}{|c|}{ Acceptance of VCT } & \multirow[b]{2}{*}{ Adjusted OR $(95 \% \mathrm{Cl})$} \\
\hline & Yes & No & OR $(95 \% \mathrm{Cl})$ & \\
\hline \multicolumn{5}{|c|}{ Knows people living with HIV } \\
\hline Yes & 199 & 49 & $0.75(0.44,1.27)$ & \\
\hline No & 162 & 30 & 1 & \\
\hline \multicolumn{5}{|c|}{ Knows people who died of HIV } \\
\hline Yes & 189 & 40 & $1.07(0.64,1.74)$ & \\
\hline No & 174 & 39 & 1 & \\
\hline \multicolumn{5}{|c|}{ Knowing HIV status brings stigma } \\
\hline Yes & 87 & 35 & $0.40(0.23,0.69)$ & $1.53(0.63,3.74)$ \\
\hline No & 274 & 44 & 1 & 1 \\
\hline \multicolumn{5}{|c|}{$\begin{array}{l}\text { If I decide for VCT, I would not have } \\
\text { community support }\end{array}$} \\
\hline Yes & 111 & 36 & $0.53(0.31,0.90)$ & $0.42(0.18,0.96)$ \\
\hline No & 250 & 43 & 1 & 1 \\
\hline \multicolumn{5}{|c|}{$\begin{array}{l}\text { If my friend turns out to be HIV } \\
\text { positive, I would slowly withdraw }\end{array}$} \\
\hline Yes & 61 & 17 & $0.74(0.39,1.42)$ & \\
\hline No & 300 & 62 & 1 & \\
\hline \multicolumn{5}{|c|}{$\begin{array}{l}\text { If ART would be available, I would be } \\
\text { willing to be tested }\end{array}$} \\
\hline Yes & 325 & 44 & $7.18(3.95,13.10)$ & $4.46(2.24,8.87)$ \\
\hline No & 36 & 35 & 1 & 1 \\
\hline \multicolumn{5}{|c|}{$\begin{array}{l}\text { If I am HIV Positive, I would tell to close } \\
\text { friend }\end{array}$} \\
\hline Yes & 240 & 37 & $2.25(1.34,3.80)$ & $0.64(0.28,1.44)$ \\
\hline No & 121 & 42 & 1 & 1 \\
\hline \multicolumn{5}{|c|}{ I would be willing to pay for VCT } \\
\hline Yes & 279 & 47 & $2.32(1.34,3.99)$ & $0.62(0.34,1.14)$ \\
\hline No & 82 & 32 & 1 & 1 \\
\hline \multicolumn{5}{|c|}{ I am willing to let partner use VCT } \\
\hline Yes & 347 & 71 & $2.79(1.03,7.44)$ & $1.34(0.42,4.29)$ \\
\hline No & 14 & 8 & 1 & 1 \\
\hline
\end{tabular}

Willingness to tell positive HIV results to close friends was found to be positively associated with VCT acceptance and those who do are twice more likely to accept VCT than those who were not willing with an OR of $2.25(1.34,3.80) \quad(\mathrm{P}$-value $<0.001)$. Seventy four percent of those seeking VCT were also willing to pay for the test. Willingness to pay for VCT was also positively associated with accepting VCT with an OR of $2.32(1.34,3.99)(p-v a l u e<0.001)$. From the total number of study subjects, $418(95 \%)$ were found to be willing to let their partner to use VCT services. Willingness to let a partner to access VCT is about three times more likely to accept VCT with an OR of $2.79(1.03,7.44)$ (Pvalue $<0.05$ ) (Table 3 ).

Among those with the appropriate knowledge about HIV/AIDS $82.8 \%$ were willing to accept VCT, while among those respondents who do not have knowledge about HIV/AIDS $75.5 \%$ were found to be willing to accept VCT. The two by two table analysis between knowledge and VCT acceptance didn't show a significant association with an odds ratio of $1.56(0.70,3.38)$ (P value $<0.23)$ (Table 4).

Among those who have perceived benefits of HIV testing, $83.5 \%$ were willing to accept VCT, while among those respondents without perceived benefits of HIV testing, 73.4\% were willing to accept VCT. The two by two table analysis between perceived benefits and VCT acceptance didn't show a significant association with an odds ratio of $1.83(0.94,3.54)(\mathrm{P}$ value $<0.06)$ (Table 4$)$.

Among those who have perceived barriers to HIV testing, $81.3 \%$ were willing to accept VCT while among those respondents without perceived barriers to HIV testing $82.4 \%$ were willing to accept VCT. The bivariate analysis between perceived barriers and VCT acceptance didn't show significant association between perceived barriers to VCT acceptance like distance, cost didn't

Ethiop.J.Health Dev 2006;20(1) 


\begin{tabular}{|c|c|c|c|c|}
\hline \multirow[b]{2}{*}{ Variables } & \multicolumn{3}{|c|}{ Acceptance of VCT } & \multirow[b]{2}{*}{ Adjusted OR (95\% Cl) } \\
\hline & Yes & No & Unadjusted OR (95\% Cl) & \\
\hline \multicolumn{5}{|l|}{ Knowledge } \\
\hline Yes & 327 & 68 & $1.56(0.70,3.38)$ & $1.57(0.69,3.39)$ \\
\hline No & 34 & 11 & 1 & 1 \\
\hline \multicolumn{5}{|l|}{$\begin{array}{l}\text { Perceived Behavior } \\
\text { Benefit }\end{array}$} \\
\hline Yes & 314 & 62 & $1.83(0.94,3.54)$ & $1.48(0.73,3.01)$ \\
\hline No & 47 & 17 & 1 & 1 \\
\hline \multicolumn{5}{|l|}{ Barrier } \\
\hline Yes & 117 & 27 & $0.92(0.54,1.60)$ & $0.95(0.55,1.63)$ \\
\hline No & 244 & 52 & 1 & 1 \\
\hline \multicolumn{5}{|l|}{ Susceptibility } \\
\hline Yes & 167 & 41 & $0.80(0.48,1.34)$ & $0.84(0.50,1.41)$ \\
\hline No & 194 & 38 & 1 & 1 \\
\hline \multicolumn{5}{|l|}{ Seriousness } \\
\hline Yes & 322 & 69 & $1.20(0.53,2.64)$ & $0.62(0.27,1.42)$ \\
\hline No & 39 & 10 & 1 & 1 \\
\hline \multicolumn{5}{|l|}{ Significant others } \\
\hline Yes & 289 & 38 & $4.33(2.52,7.46)$ & $4.48(2.62,7.66)$ \\
\hline No & 72 & 41 & & \\
\hline
\end{tabular}

show significant association with VCT acceptance with an OR of $0.92(0.54,1.60)(\mathrm{P}$-value $=0.76)$ (Table4).

Among those who have perceived susceptibility to HIV testing, $80.3 \%$ were willing to accept VCT, while among those respondents without perceived susceptibility of HIV testing, $83.6 \%$ were willing to accept VCT. Perceived susceptibility to HIV/AIDS also didn't show significant effect on determining VCT acceptance with an OR of $0.80(0.48,1.34)(\mathrm{P}$-value $=0.36)($ Table 4$)$

Among those who have perceived seriousness to HIV testing, $82.4 \%$ were willing to accept VCT, while among those respondents without perceived seriousness of HIV testing, $79.6 \%$ were willing to accept VCT. Regarding perceived seriousness of the disease, HIV/AIDS also was found not to have significant association with VCT acceptance with an OR of $1.20(0.53,2.64)$ (Pvalue $<0.63$ ) (Table 4).

Among those who said their VCT acceptance will be influenced by significant others like religious leaders community leaders, sexual partners, parents and friends, $88.4 \%$ were willing to accept VCT, while among those who said their VCT acceptance will not be influenced by significant others $63.7 \%$ were willing to accept VCT. The influence of significant people like religious leaders, community leaders, sexual partners, parents and friends was four times likely to make people accept VCT with an OR $4.33(2.52,7.46)(\mathrm{P}$-value $<0.001)$. After controlling for the effect of socio-demographic factors, the role of significant others in affecting VCT acceptance positively remained with an OR of $4.48(2.62,7.66)$ (pvalue $<0.001)$ (Table 4).

\section{Discussion}

VCT is one of those approaches that are adopted at the national level for HIV/AIDS Prevention and Control. This study tried to look into some of the important factors that affect the acceptance of VCT among the different professional and community groups in the study area. There was no significant difference in VCT acceptance between the urban and rural population in this study. As this study is mainly focused on urban areas, the rural population is underrepresented. This underrepresentation would make it difficult to identify any urban-rural differential in this particular study.

This study showed the age group of 15-19 to be the most receptive group to VCT services compared with the other age groups. The age group between 15 and 19 is the most affected group by HIV/AIDS in Ethiopia which has the highest prevalence of HIV infection (1). Targeting this age group for VCT services would greatly reduce the risk of HIV/AIDS, which is evidenced in this group. The national VCT Policy of Ethiopia considers the lower age of consent for VCT to be 18 years (2). The significant positive association of the younger age group may be due to the better access to information through public gatherings, organizations, clubs and using other means of institutional media. This finding is the same with studies done in other places in Ethiopia $(11,13,14,15)$.

This study demonstrated that educational status didn't show statistically significant association with VCT 
acceptance. This finding is not consistent with the findings in other studies $(5,10)$. A study done in Jimma found out that better educational status was associated with a higher chance of VCT acceptance (13). The reason for the lack of association between educational status and VCT in this study could be due to the low number of study subjects with lower educational status or illiterates.

The study indicated that health professionals and high school teachers were found to have less acceptance of VCT compared with the other community groups included in the study. This could be due to the fact that as people's knowledge increases about the serious health consequences to the extent of death and the society's reaction to the disease, which is stigma and discrimination, people could decline to accept VCT despite good knowledge. It is also shown in a number of studies that knowledge does not necessarily bring about attitudinal change and practice of the desired behavior. Although there are important benefits to knowing one's HIV status, HIV infection, in many communities, is a stigmatizing condition and this can lead to negative outcomes for people following testing. People with HIV may experience social rejection and discrimination (16, 17).

This study identified the availability of ART as a positive predictor of VCT acceptance. The provision of ART would have a significant effect in prolonging life and this would have an impact on the community in creating positive attitudes and acceptance towards the service. Making every effort to make ART available would increase VCT acceptance by all community groups.

The study revealed the importance of religious leaders, couples, friends and families as reinforcing factors towards VCT acceptance. Normative belief generally focuses on what an individual believes other people, especially influential people, expect him/her to do. Perception of social or peer norms concerning the acceptability of VCT is an important determinant of VCT acceptance (18).

Seventy four percent of the people in this study were willing to pay for VCT services, and this finding is greater as compared to $13 \%$ reported in Kenya and $24 \%$ in Uganda (19). The greater proportion of study subjects who are willing to pay for VCT services is a good indication of the potential for service expansion. Expanding VCT services at a commensurate cost would help to increase service accessibility without jeopardizing VCT acceptance.

The most important factors identified in this study to influence the acceptance of VCT were being in the age group of 15-19, availability of ART, the influence of significant others like (religious leaders, peers, friends, and teachers), stigma associated with testing and the presence or absence of community support towards acceptance of VCT.

One of the limitations of this study was that the sampling method used was non-probability purposive sampling, which may affect the representative of the study. Due to resource implications, the study considered different professional and community groups in the two administrative zones, which may not represent the selected group. An outcome measure, which is intention to accept VCT, can change for various reasons, as it is not a hard outcome. Another limitation is that the study was mainly focused on urban areas, and the rural population is underrepresented.

Based on the findings, the following recommendations were made. Involving closely related people and influential personalities is an important method to enhance social acceptance of voluntary counseling and testing. The most vulnerable group to HIV, which is the age group between 15-19 years, is the most receptive group of VCT and hence efforts should be made to extend the service to them. The lower age limit for giving VCT consent needs to be revised by the concerned policy makers. Efforts should be made to design their responsiveness towards VCT acceptance. Making every effort to make ART available would increase VCT acceptance by all professional groups, and efforts targeted at reducing stigma by all professional and community groups need to be addressed in order to deliver reliable and sustainable VCT related services. Further research using larger sample sizes and probability sampling techniques is recommended.

\section{Acknowledgment}

We are greatly indebted to the EPHA-CDC project for financing this study and for the critical comments that helped us to improve the outcome of our work. We acknowledge the unreserved efforts of the supervisors in materializing this research. This study would not have been a reality with out our study participants who gave us their precious time and responded genuinely to the questionnaire.

\section{References}

1. MOH. National Guidelines for Voluntary HIV Counseling and Testing in Ethiopia, Addis Ababa, Ethiopia. 2000.

2. UNAIDS. Reports on the Global HIV/AIDS Epidemic: Global Report, $4^{\text {th }}$ edition 2004.

3. MOH. AIDS in Ethiopia, Fifth Edition, Addis Ababa, Ethiopia, 2004.

4. WHO. Sexual relations among young people in developing countries: Evidence from WHO case studies, World Health Organization, Geneva, Switzerland, 2001. 
5. Abdi D, Ahmed A, Alemayehu W. Perception of risks of sexual activities among out of school adolescents in South Gondar Administrative Zone, Amhara Region. (Paper presented on the $14^{\text {th }} \mathrm{EPH}$ Annual Public Health Conference, 15-17 October 2003, Addis Ababa)

6. Zenabu A. Knowledge, attitude and behavior (KAB) on HIV/AIDS/STDs among workers in the informal sector in Addis Ababa. Ethiop. J. Health Dev. 2003; 17(1): 53-61.

7. Cherenet A, Ishmail S, Mitike G. Perceived sufficiency and usefulness of IEC materials and methods on HIV/AIDS among high school youth in Addis Ababa. (paper presented on the $14^{\text {th }}$ EPHA Annual Public Health Conference, 15-17 October 2003, Addis Ababa)

8. Sara D, Yosef T. Cross-sectional study on HIV/AIDS related knowledge and practice among the military student of Defense University. (Paper presented on The 14th EPHA Annual Public Health Conference, 15-17 October 2003, Addis Ababa).

9. Mulugeta E. Patterns of Sero prevalence. Among clients attending Beth Zatha "Know you self" VCT project. (Paper presented on The $14^{\text {th }}$ EPHA Annual Public Health Conference, 15-17 October 2003, Addis Ababa).

10. UNAIDS. Voluntary Counseling and Testing (VCT); P 12:2000.

11. Mulugeta E. Socio-demographic characteristics, sexual behavior and reasons for attending VCT service at Beth Zatha VCT Project. (Paper presented on The $14^{\text {th }}$ EPHA Annual Public Health Conference. 15-17 October 2003, Addis Ababa).

12. Zerihun D. Trends of HIV infection and profiles of voluntary HIV counseling and testing (VCT) acceptance in seven branch clinics of the Family Guidance Association of Ethiopia. (paper presented on The $14^{\text {th }}$ EPHA Annual Public Health conference, 15-17 October 2003, Addis Ababa.

13. CSA. Demographic and Health Survey, Central Statistical Authority, Addis Ababa and ORC Macro, Calverton, Maryland USA: CSA \& ORC Macro, 2000.

14. Getachew D, Tsenuel G, and Belaineh G. Seroprevalence of HIV-1 and possible factors affecting prevention of vertical transmission of HIV in antenatal care attendants, Jimma University hospital. (paper presented on The $14^{\text {th }}$ EPHA Annual Public Health Conference. 15-17 October 2003, Addis Ababa).

15. Fishbein M, and Ajzen I. Beliefs, attitudes, infection and behavior: An introduction to theory and research. Reading, MA: Addison. Wesley, 1975.

16. Karim Q, Karim S, Soldan K, Zondi M. Reducing the stigma of HIV infection among South African sex workers: Socioeconomic and gender barriers, American Journal of Public Health 1995;85(11): 1521-5.

17. Baggaley R, et al Barriers to HIV counseling and testing (VCT) in Chawama, Lusaka, Zambia, 9th International Conference of AIDS and STDs in Africa. December 1995.

18. UNAIDS. The impact of voluntary counseling and testing: A global review of the benefits and Challenges, 96 p, 2000.

19. UNAIDS. WHO/UNAIDS Technical Consultation on Voluntary HIV Counseling and Testing: Models for Implementation and Strategies for Scaling of VCT Services 29 p, 2002. 
24 Ethiop.J.Health Dev.

Ethiop.J.Health Dev 2006;20(1) 